NBER WORKING PAPER SERIES

SECONDARY PHARMACEUTICAL PATENTING:

A GLOBAL PERSPECTIVE

Bhaven N. Sampat

Kenneth C. Shadlen

Working Paper 23114

http://www.nber.org/papers/w23114

\author{
NATIONAL BUREAU OF ECONOMIC RESEARCH \\ 1050 Massachusetts Avenue \\ Cambridge, MA 02138 \\ January 2017
}

We appreciate ESRC grant (ES/K010999/1) The views expressed herein are those of the authors and do not necessarily reflect the views of the National Bureau of Economic Research.

NBER working papers are circulated for discussion and comment purposes. They have not been peer-reviewed or been subject to the review by the NBER Board of Directors that accompanies official NBER publications.

(C) 2017 by Bhaven N. Sampat and Kenneth C. Shadlen. All rights reserved. Short sections of text, not to exceed two paragraphs, may be quoted without explicit permission provided that full credit, including $\odot$ notice, is given to the source. 
Secondary Pharmaceutical Patenting: A Global Perspective

Bhaven N. Sampat and Kenneth C. Shadlen

NBER Working Paper No. 23114

January 2017

JEL No. I18,O3

\begin{abstract}
$\underline{\text { ABSTRACT }}$
Pharmaceutical firms' use of secondary patents to extend periods of exclusivity generates concerns among policymakers worldwide. In response, some developing countries have introduced measures to curb the grant of these patents. While these measures have received considerable attention, there is limited evidence on their effectiveness. We follow a large sample of international patent applications in the US, Japan, the European Patent Office, and corresponding filings in three developing countries with restrictions on secondary patents, India, Brazil, and Argentina. We examine cross-country comparisons of primary vs. secondary grant rates, consider the differential fates of "twin" applications filed in multiple countries, and undertake detailed analyses of patent prosecution in the three developing countries. Our analyses indicate that measures to restrict secondary patents in developing countries are having limited impact. In none of these three countries are specific policies toward secondary patents the principal determinant of grant rates. Our analyses also suggest the importance of other procedural aspects of patent systems, beyond the formal policies targeting secondary applications, that affect outcomes for these applications in developing countries.
\end{abstract}

Bhaven N. Sampat

Department of Health Policy and Management

Columbia University

600 West 168th Street, 6th Floor

New York, NY 10032

and NBER

bns3@columbia.edu

Kenneth C. Shadlen

Department of International Development

London School of Economics

and Political Science (LSE)

k.shadlen@lse.ac.uk 


\section{Secondary Pharmaceutical Patenting: A Global Perspective}

\section{Introduction}

Taking out multiple patents on different aspects of a drug in order to cordon off competitors is standard practice in pharmaceuticals. In addition to primary patents, firms commonly attempt to acquire secondary patents on alternative forms of molecules, different formulations, dosages, and compositions, and new uses. Devising patenting strategies to extend periods of protection is an essential aspect of "life cycle management" in the pharmaceutical industry (Burdon and Sloper 2003; Howard 2007; European Commission 2009; Sternitzke 2010; Ellery and Hansen 2012; Kapczynski et al. 2012). This paper discusses policy challenges raised by secondary patenting, provides comparative data on secondary patent grant rates, and evaluates the effectiveness of restrictions on secondary patents in developing countries.

While firms increasingly attempt to obtain secondary patents, policymakers have grown concerned about their effects, since they can extend periods of exclusivity beyond the dates in which protection would otherwise lapse if the only protection came from the primary patent on the molecule. Some have argued that patents on alternative molecular forms, formulations, or uses are of lower "quality" than primary patents too, in that they are less likely to be novel or manifest inventive step (Correa 2007; Kesselheim 2007; Eisenberg 2008). And as with more general debates over patent quality (Jaffe and Lerner 2004; de Rassenfosse et al 2016; GAO 2016), there are concerns that patent offices worldwide may erroneously grant secondary applications that don't warrant patentability, but once granted restrict competition.

Secondary patents are a particular source of concern in developing countries, where pharmaceutical patenting is new. The World Trade Organization's (WTO) 1995 Agreement on Trade-Related Aspects of Intellectual Property Rights (TRIPS) required developing countries to change their patent laws to be more like those in developed countries. Prior to TRIPS few developing countries allowed pharmaceutical products to be patented. Doing so is now obligatory for nearly all WTO members. ${ }^{1}$

While TRIPS universalizes pharmaceutical patenting, some developing countries have exploited flexibilities built into the agreement to try to limit the grant of secondary patents. Three prominent examples of countries doing so are India, Brazil, and Argentina. Fearing the effects that secondary patents might have on pharmaceutical markets and access to medicines, and worried by the difficulties of circumventing or removing patents once granted, each of these countries introduced provisions to restrict secondary patenting.

These countries' approaches toward secondary patents have been championed by academics, civil society groups and non-governmental organizations, and cited as models to be emulated (Reichman 2009; Kapczynski 2013; South Centre 2011; UNAIDS 2011). They have also been criticized by the pharmaceutical industry as unfair limitations on their abilities to obtain patents

${ }^{1}$ Thirty-four WTO members classified as "Least Developed Countries" are exempted from this obligation until 2033. Before TRIPS many developing countries allowed for process patents in pharmaceuticals, but not product patents. 
(PhRMA 2016). ${ }^{2}$ Though there are policy concerns, and some data that many secondary patents are issued in developing countries (Abud et al 2015 ,Correa et al 2011), there is little evidence on the share of secondary applications granted and the effectiveness of countries' specific restrictions.

This paper evaluates the effects of measures to limit secondary patents in India, Brazil, and Argentina on patent office outcomes in these countries. We do so in three ways. First, we compare differences between primary and secondary patent grant rates in these countries to differences in three patent offices (the U.S., EPO, and Japan) that do not have measures toward secondary patents. If the developing country policies are functioning effectively, we should observe differences across countries in the differential grant rates between primary and secondary patents. Second, we compare grant rates for secondary patents in developing countries for "twins," the same applications filed in different jurisdictions. Exploiting the twins nature of international patent applications is increasingly common for developed countries (Jensen et al 2006; Hopkins et al 2007; Lemley and Sampat 2012; Webster et al 2014; de Rassenfosse et al 2016; Christie et al 2016), but few analyses have done so for developing countries (Sampat and Amin 2013; Sampat and Shadlen 2015a). Third, since grant rates may be a blunt indicator of policy effectiveness, we provide data on the details of patent prosecution for secondary patent applications filed in the developing countries. This allows us to examine the role that the specific policies are having, in relation to other influences on secondary patenting grant rates. These final analyses build on and extend recent work in the U.S. that uses prosecution history data to get "inside the black box" of patent examination, to provide insights on the functioning of patent systems, beyond what can be learned from grant rates alone (Drahos 2010; Lemley and Sampat 2012; Carley et al 2015; Frakes and Wasserman forthcoming).

We find that developing countries' measures to restrict secondary patents are having less impact than one might expect from the considerable attention (positive and negative) they attract. Neither India nor Brazil exhibit lower grant rates for secondary patents than for primary patents, which is a differential that we would expect to observe if these countries' measures were having their intended impact. These results are robust across the overall sample, and the sets of twin applications. Though we do observe this differential in Argentina, detailed analyses of prosecution suggest that in none of these three countries are specific policies toward secondary patents the principal determinant of grant rates. In investigating this, we find suggestive evidence that long patent office backlogs in the developing countries give applicants time to learn about the importance and quality of their applications, leading them to abandon applications deemed not worth pursuing.

In the following section we provide a general overview of the challenges posed by secondary patents globally, discuss why secondary patenting is a particularly salient policy issue in developing countries where pharmaceutical patents are new, and describe the policies that India, Brazil, and Argentina have enacted to limit the grant of such patents. In Section 3 we discuss the data sources we use to provide comparative evidence on secondary patent grant rates and to

${ }^{2}$ One of the controversial aspects of the proposed Trans-Pacific Partnership had been the prohibition on national restrictions on some forms of secondary patents. 
assess the roles played by the developing countries' restrictions. In Section 4 we present our empirical results, examining cross-national grant rates, grant rates for "twin" applications, and detailed analyses of secondary patent prosecution. Section 5 discusses these results. Section 6 synthesizes the main findings of the paper, addresses the limitations of the study, and points to avenues for future research.

\section{Secondary Patents and Public Policy}

Secondary patents can restrict competition, deny consumers the benefit of generic entry, and thus allow for supra-competitive prices. While this is true of all patents, the grant of secondary patents draws particular criticism from those who believe they represent less research investment than novel molecules, and thus do not warrant patent protection (Correa 2007; Correa 2014). Related to this, because applications for secondary patents are typically filed after applications for primary patents, and patents last twenty years from the date of application, secondary patents, if granted, can potentially extend periods of market exclusivity. Pharmaceutical firms use secondary patents to retain exclusive rights to valuable, revenue-generating drugs for as long as possible, a strategy that has been attributed to the high costs of research and development, the low success rate in creating products that work in the lab and clinic and can gain regulatory approval, and the fact that significant portions of available patent periods will ordinarily have lapsed before successful products ever get on the market (European Commission 2009). While in industry the use of secondary patents to extend periods of market exclusivity is referred to as "life cycle management" (e.g. Burdon and Sloper 2003, Ellery and Hansen 2012), critics use the more pejorative term "evergreening" (Rathod 2010; Correa 2014).

Even in the absence of specific policies targeting secondary patents, legal scholars believe that conventional patent standards, that an invention must be novel and demonstrate inventive step (in the USA, be "non-obvious") ought to make secondary patent applications more difficult to obtain (Eisenberg 2008). But there is also concern that resource-constrained patent offices commonly grant low "quality" patents (Jaffe and Lerner 2004), i.e. patents that do not satisfy conventional patent standards and that, with more rigorous scrutiny, would have been rejected. Some have argued that the U.S. patent system is particularly permissive, on account of the incentives facing examiners to grant patents and its unique continuation practice that can reward applicants who are persistent (Lemley and Moore 2004; Amin and Kesselheim 2012), though the US is not alone in being criticized in this regard (Moir 2013). The perception that the lax application of traditional patent standards can contribute to excessive granting of low-quality secondary patents in developing countries is widespread too (Drahos 2008; Drahos 2010; Correa 2007; Correa 2014; Reichman 2009, Löfgren and Williams 2013).

One way to address the problems that may be created by the granting of secondary patents is to invalidate them via litigation, as is common in the U.S. and many developed countries (Hemphill and Sampat 2011). In developing countries, however, smaller markets and greater resource and information asymmetries between patent holders and potential challengers make this a less attractive solution (Sampat and Shadlen 2015a). Rather than relying on litigation to invalidate low-quality secondary patents after they have been issued, countries implementing new patent laws under TRIPS have been encouraged to introduce measures to address secondary patents at the point of examination. Such measures try to limit the grant of secondary patents in the first 
place, reflecting a belief that, in the language of Drahos (2008), prevention is better than treatment. ${ }^{3}$ Although secondary patents in pharmaceuticals (and other fields) may be more vulnerable to rejection or invalidation under traditional patentability standards (e.g. novelty and inventive step) as noted above, this approach reflects a concern that ordinary examination practices are not enough, and additional restrictions specifically targeting secondary patents are needed.

The three most prominent attempts to limit secondary patents at the point of examination are in India, Brazil, and Argentina. India took full advantage of the transitional provisions in TRIPS, which allowed countries to wait until 2005 to begin granting pharmaceutical patents.

Accordingly, India began accepting applications in 1995, when TRIPS formally came into effect, though these were held waiting in a "mailbox" until 2005. In the final amendments to its new TRIPS-compliant patent law in early 2005, as the country began to examine pharmaceutical patent applications, India introduced Section 3(d), a provision that was explicitly designed to minimize the grant of secondary patents (Basheer and Reddy 2008; Kapcyznksi 2009). According to Section 3(d), new forms of known substances are not eligible for protection unless the applicant can demonstrate increased "efficacy."4

Brazil introduced pharmaceutical patents in 1997, and in 2001 the new patent law was reformed to condition the grant of drug patents not only on the approval of the Brazilian patent office (INPI), but also on the "prior consent" of the Ministry of Health's surveillance agency (ANVISA). When the system was put in place there was confusion about how exactly the health agency would carry out its new task. ANVISA subsequently decided to use its authority to try to limit the grant of secondary patents. The health agency created its own intellectual property division, and developed its own examination guidelines, more restrictive than INPI's, specifically targeting secondary patents (Basso 2006; Silva 2008; Shadlen 2011; Correa 2014).

Under the arrangements that were in place until 2012, the examination process began at the patent office. When INPI determined that the patent should not be granted, then the application was rejected and the process ended. However, when INPI determined that the patent should be

\footnotetext{
${ }^{3}$ Another reason why secondary patenting has particular salience in developing countries relates to the timing of TRIPS implementation. Because of the transition provisions in TRIPS, countries were not required to grant patents with priority dates (first global filing date) before 1995. This means that for many drugs that were launched in the 1990s and 2000s, primary patents are not eligible, despite the global spread of pharmaceutical patenting, and the only patent protection available in developing countries would be via secondary patents (Sampat and Shadlen 2015b). This transitional feature heightened the stakes of policy choices about secondary patents.

${ }^{4}$ Section 3(d) was a surprise to most observers, including the pharmaceutical industry. It has since been the source of much controversy. The provision was (unsuccessfully) challenged in the Indian Supreme Court by Novartis, following the Indian Patent Office's rejection of a secondary patent on a cancer drug "Gleevec" (imatinib mesylate). The Novartis case galvanized opposition to 3(d) from the transnational pharmaceutical industry, and also vigorous defense of the provision from civil society organizations, health activists, and international organizations.
} 
granted, the application was passed to ANVISA for the health agency's examination team to make its own judgment. If ANVISA issued its consent, INPI then granted the patent; if ANVISA withheld its consent, INPI was prohibited from granting the patent (notwithstanding its original favorable evaluation). The Prior Consent system was revised in 2012, reversing the order of operation, but the core feature of Brazil's system - pharmaceutical patents need to be approved by both the INPI and ANVISA to be granted - remains in place. ${ }^{5}$

In Argentina, pharmaceutical products became patentable in 2000. In 2002, the patent office issued new examination guidelines that barred patents on one type of secondary patent, those claiming second medical uses. Then, in 2012, the patent office issued new and significantly more restrictive guidelines that instruct examiners to reject most forms of secondary pharmaceutical patents. Argentina's approach toward secondary patents differs from that of India and Brazil in terms of coverage. For most of the period in our analysis, the prohibition on second medical uses is the sole measure designed to limit secondary patents. The more restrictive guidelines are only in place for applications examined as of May 2012.

As discussed above, these provisions have received considerable attention, but little research has been conducted on their effects. Berndt and Cockburn (2014), for example, assume that Section $3(d)$ is restricting patent grants in India but their research design does not allow them to not provide direct evidence on this. Basso (2006), Shadlen (2011) and Barbosa (2013) analyze the conflict between INPI's and ANVISA's approaches to secondary patents in Brazil, but without systematically assessing the effects of the dual examination arrangements on patent grant outcomes. Other academics have expressed concerns that patent examiners in developing countries, tied into global examination networks, working under severe resource constraints, and facing pressures to clear the large inflow of applications, may not effectively enforce laws and guidelines and there may be significant gaps between laws on the books and patent prosecution in practice (Kapycynski 2009; Drahos 2010). Yet there is little direct evidence of this either. Drahos (2010) shows how the transnational integration of patent offices generates a common "interpretive examination culture," but the analysis does not provide data on convergence in terms of patent office outcomes.

A previous study examining Indian and Brazilian patent applications on about 150 drugs launched between 1996 and 2004 with at least one U.S. patent, found these provisions were rarely used (Sampat and Shadlen 2015a). However, that work focused on a small number of applications with various special characteristics (including that they tended to be older applications, and they were associated with "successful" drugs already on the market that had U.S. patents). Moreover, that study was only able to ensure similarity of applications for a small number of cases, making comparing grant rates on secondary patents difficult. Most importantly, by focusing only on India and Brazil there was no baseline against which to assess grant rates for secondary patents. Nor do we know much about the Argentinean approach. One earlier study has examined secondary patenting in Argentina (Correa et al, 2011), but because this paper focuses

${ }^{5}$ Under the new workflow, pharmaceutical patent applications are first sent to ANVISA: if ANVISA rejects, the examination process is to end there; if ANVISA approves, the application is then examined by INPI. 
only on granted patents it cannot provide insight into how the patent office's approach to secondary applications functions.

In this paper we use a novel dataset of international patent applications, code each application as primary or secondary, and identify outcomes in each of the developing countries, and, as a basis for comparison, in three developed country patent offices. In addition to providing descriptive results on cross-national grant rates for secondary patents, we examine the effectiveness of the restrictions in Argentina, Brazil, and India in several different ways. The following section describes the dataset and research strategy.

\section{Data}

\section{PCT applications and coding}

The majority of global pharmaceutical patent applications are filed through the Patent Cooperation Treaty (PCT), which allows single applications to be deposited in multiple jurisdictions after undergoing preliminary analysis by an International Searching Authority. Our analysis focuses on grant rates for "national phase" applications in each country - the U.S., Europe, ${ }^{6} \mathrm{Japan}, \mathrm{Brazil}$, and India - that emanate from PCT applications. In the case of the one non-PCT member, Argentina, we use the Argentinian equivalents of "national phase" filings."

Using the World Intellectual Property Organization's Patent Statistics database, we identified all PCT applications filed between 2000 and 2002 that had at least one International Patent Classification of A61K or C07D, the main classes associated with drugs. From these, we focused on applications that were filed (either as original filings or as national phase filings through the PCT) at the US, European and Japanese patent offices. Applying these criteria left 15,815 applications. We focused on the years 2000 to 2002, to allow a long window to observe outcomes. (Otherwise, many applications would remain pending, especially in the developing countries with large patent office backlogs.) Another benefit of focusing on this time period is that the Indian and Brazil national phase applications from PCT applications filed during these years would have been submitted before Section 3(d) was introduced or ANVISA's secondary patent restrictions were fully implemented, and before the most restrictive Argentinian guidelines were enacted, limiting the effect of selective filing on our results.

Since our research involved working with individual applications, to keep the analyses manageable we further restricted the set to those filed between January and July. Patent classifications are known to be noisy. Scanning this set revealed it contained many applications that were not actually for pharmaceuticals; we consulted the Thomson Reuters "Chemical Patent

\footnotetext{
${ }^{6}$ Because of a shared European patent office, the EPO, we refer to "Europe" as if it were a country.
}

${ }^{7}$ In the Appendix we describe the steps taken to map PCT applications to their national versions, and our approach for determining the outcome of each national application. 
Index" (CPI) code for each application and used these codes to narrow to true pharmaceuticals, resulting in a final set of 5,193 applications. ${ }^{8}$

In some of our analyses, we will examine matched "twin" applications, i.e. the same PCT applications that have national phase entries in each of the PCT countries (and equivalent national applications in the non-PCT country, Argentina). While the specific claims filed in individual jurisdictions vary slightly, by and large these applications are substantively similar, if not always "identical" twins.

For our analyses we will need to know which of the PCT applications (and by extension, the national phase filings that result) include primary claims or only secondary claims. We had a pharmaceutical patent attorney code each of the applications, using a coding guide adapted from Hemphill and Sampat (2011). The Appendix includes the first pages of the coding guide. About 8 percent of the applications contained only process claims. We dropped these, since our focus is on product patenting. Of the remaining 4,765 applications, roughly 38 percent were coded as including a novel active ingredient claim and thus were classified as "primary," and 62 percent had no novel active ingredient claims and were classified as "secondary."

\section{National outcomes}

We collected information on whether each PCT application was filed and granted in each country. For the 5 PCT members, we collected information on any national phase applications filed in these patent offices via the PCT. Since Argentina is not a member of the PCT, there we focus on any national applications that are equivalents of the PCT applications. For expositional convenience, though with a slight abuse of terminology, we refer to all of these, including those filed in Argentina, as "national phase" applications. We determined whether each of the national phase applications was granted in each country, as of 2015. In cases where a given PCT spawned more than one application (including, for example, through "continuation" and "divisional" applications) we determined whether any of the applications were granted. ${ }^{9}$

For the three developing countries we recorded outcomes beyond overall grant rates, to distinguish between applications that were rejected, abandoned or withdrawn, and those still pending. In India and Brazil, we also collected detailed information on prosecution histories, including, for those that were not granted, the specific reasons for non-grant (India) and role of ANVISA in the process (Brazil). In Argentina we examined the fate of use patents and distinguished between those applications reviewed before and after the patent office's new

${ }^{8}$ The CPI codes are based on expert coding of the applications. Each application can have many CPI codes. We restricted the set of patent applications to those with at least one "B" (Pharmaceutical) coding, dropping 826 applications. Among the remaining applications, we also determined which were likely biotechnology-related (those coded as B04-E, F, G or D05-H). We also dropped these applications (about a third of the total) since our focus here is on small molecule drugs where secondary patents are more prevalent and regarded as potentially important impediments to competition among multiple suppliers.

9 These "child" applications contain subject matter from previously-filed "parent" applications. 
examination guidelines came into effect. This additional information helps us better understand the role of the countries' approaches toward secondary patents in determining outcomes for the national phase applications.

It is important to emphasize what this sample excludes. In focusing on national phase applications, we are not including the underlying priority applications on which the PCT was based. This is not an issue for developing countries, since almost all applications are filed there based on the PCT, but for the US, EPO, and Japan only applications filed via the PCT are in our sample. ${ }^{10}$

\section{Application importance}

In addition to any laws or policies regarding secondary patents, applicants' levels of effort in pursuing patent protection also may influence national outcomes. This varies with the importance of the invention, based on information at the time of filing and information that accumulates over time.

One measure of importance is family size: the number of countries in which an application is filed, based on data from to the Derwent World Patents Index (DWPI). Family size is a commonly used measure of invention importance, based on the expectation firms will file their more important inventions more broadly (Lanjouw et al 1998).

Given long patent office backlogs and slower prosecution in developing countries (Schultz and Madigan 2016), most applications may not be examined until well after they were filed and even granted in many developed countries, we can also look at a measure of importance further into the lifecycle, whether the patent was granted in the U.S., and, if so, if it was renewed. For national phase applications filed and granted at the USPTO, we also collected information from the USPTO on they were renewed (as of October 2015) or allowed to lapse (USPTO, 2015).This allows us to distinguish, among the applications in our sample that were filed at the USPTO, between those never granted, those granted but allowed to lapse (reflecting diminished importance and effort over time), and those granted and maintained (reflecting the greatest degree of importance and effort).

Table 1 provides basic descriptive data for the full sample. Of the 4,765 PCT applications, 62 percent are secondary. Recall that our sample is based on PCT applications with original (priority) or national phase filings in the U.S., EPO, and Japan. About two thirds of the PCTs had national phase applications in the U.S., over 90 percent in Japan, and nearly all in Europe. The share with national phase applications is much lower in the developing countries ( 24 percent in India, 35 percent in Brazil, and 20 percent in Argentina). On average the applications in our set

${ }^{10}$ In practice, almost all PCT applications filed at the EPO "go national" in the EPO through the PCT. This is because applications from member countries that are filed at the EPO automatically receive new "Euro-PCT" application numbers. About a quarter of PCT applications filed through the US go national in the US via the PCT (typically these are based on provisional priority applications in the U.S. that are then abandoned), and the analogous figure is 55 percent for Japan. 
were filed in nine countries. And for the 3,184 PCT with US national applications, 29 percent were granted and renewed to date.

$$
- \text { Table } 1-
$$

\section{Secondary Pharmaceutical Patenting}

We use these data in four ways. First, we consider how secondary patent grant rates vary across countries, conditional on filing and by the two measures of invention importance. Doing so provides us with a baseline for understanding these countries' grant rates, and a point of departure for our subsequent focus on the effectiveness of specific instruments to restrict secondary patents. Second, we examine cross-country differentials between grant rates for primary vs. secondary patents. If national restrictions on secondary patents are functioning effectively, we should see a larger "difference in differences" between primary and secondary grant rates in countries with such restrictions than in countries without. Third, we examine the fate of the same applications filed in different countries. This analysis of "twins" allows us to control for applicants' propensity to file different applications in different countries, and thus make sure that the results we observe reflect differences in how countries treat secondary applications rather than the characteristics of the applications filed nationally. Fourth, we provide detailed analyses of secondary patent prosecution outcomes in the three developing countries, extending our focus beyond grant rates. Doing so provides a complementary "bottom up" lens on the specific roles played by these countries' measures to restrict secondary patents.

\section{Cross-national Comparisons of Grant rates}

Of the 2,964 secondary applications, 971 had national phase filings in Brazil through the PCT, 641 in India, 2,047 in the US, 2,956 in the EPO, and 2,735 in Japan, and 444 had equivalents filed in Argentina. Figure 1(a) shows grant rates for secondary applications in each country, conditional on filing. We count a PCT application as "granted" in a country if any national phase application (including continuations or divisionals) is granted. The U.S. grants about half of the secondary applications, roughly the same as in Europe. Surprisingly in view of the controversy surrounding Indian restrictions on secondary patenting, India is the median country in terms of granting secondary patents; Japan has a much lower grant rate than India. The lowest grant rates are in Argentina and Brazil.

\section{- Figure $1-$}

Grant rates are the result of several factors, including the types of applications filed in a country, patent laws and guidelines, how laws and guidelines are enforced, and patent office processing speed. We will consider the role these factors may have in explaining overall trends in more detail below. For now, a simpler explanation for differences may be that applicants try harder on some applications than others. To examine whether the differences across countries reflect only applicant effort, we examined how grant rates vary across the family size distribution.

Figure 2 shows that grant rates increase with family size in all countries. However, the gradient is notably less steep in the South American countries. If we focus on the top decile of the family size distribution (applications filed in 25 or more countries), several things stand out. The EPO 
has the highest grant rate for these important applications ( 90 percent), followed by the US (granting 81 percent). India is still the median, though the grant rate at the top of the distribution is nearly 60 percent (compared to the 42 percent that we saw above, for all Indian applications). Even at the top of the distribution, only 15 percent of secondary applications filed in Argentina, and 8 percent filed in Brazil, were granted.

- Figure $2-$

Family size is a measure of application importance at the time the application is filed. A complementary measure is U.S. maintenance status, which can shine a light on importance as applicants obtain additional information after original filing decisions are made. Applications that are granted in the U.S. and maintained there are likely to be ones that drug companies most care about, for these applications are likely to be associated with drugs that have passed product development and perhaps even market entry tests. Figure 3 shows grant rate in the five other countries based on U.S. maintenance status.

Again we see sharp gradients, with applications granted in the U.S. and maintained having much higher grant rates in other countries than applications that are not granted, or granted and allowed to lapse. As with the family size, the basic rank ordering of countries by grant rate of secondary applications is similar at the top of the distribution to what we saw in Figure 1. Effort appears to matter in Argentina and Brazil, as elsewhere, but even for these applications that are granted and maintained in the U.S., grant rates in the two South American countries are low.

- Figure $3-$

The data presented so far suggest that secondary patents are easiest to obtain in the U.S. and Europe and hardest in Argentina and Brazil, with India and Japan in between, and that in all countries more important inventions, by either measure of importance, fare better. However, the fact that differences across countries in grant rates for secondary patents persist, even for the most important inventions, calls for further explanation.

\section{Understanding the Differences in Developing Countries}

Differences in national grant rates, overall and conditioned on importance, may not necessarily tell us about the permissiveness of each country towards secondary applications, or, for the countries with restrictions, their effectiveness. There are other reasons that grant rates may vary, including the speed by which applications are examined and other attributes of national patent offices, and the efforts that applicants make (on account of the economic importance of particular markets, for example, or new information obtained about a drug's promise).

One way to account for country-specific factors that affect outcomes is to compare differences in secondary grant rates to differences in primary grant rates. Even if we saw differential grant rates by type of application, it would be important to compare these to differential grant rates in countries without specific restrictions on secondary patents, since secondary patents may be more vulnerable to rejection anyhow (through novelty and inventive step), even absent specific policies targeting them. That is, it is useful to look at the difference in differences: comparing the 
difference between secondary and primary grant rates between countries that do and do not have specific restrictions. Comparing Figures 1(a) and 1(b) allows us to do this. Here we see that neither India nor Brazil has a lower secondary grant rate than a primary grant rate, an observation that is not what we would expect if restrictions targeting secondary patents were effective. By contrast in Argentina there is a 7 percentage point differential, which is greater than that in two of the developed country patent offices (EPO and JPO) but much smaller than that in the U.S. ${ }^{11}$

Beyond differences in national characteristics of patent systems, which the comparison to primary patents aims to account for, another issue that may bias cross-country comparisons is that not all the PCT applications are filed in all countries. As a result, the outcomes may be reflecting as much about characteristics of the applications filed in each country as the countries' examination practices. To provide better comparability, Figures 1(c) and 1(d) show analogous data for "twin" applications where the same PCT is filed in all six countries. For secondary twins, in 1(c) we see the same patterns: grant rates are highest in the EPO and US and lowest in Argentina and Brazil, with India and Japan in the middle. What about the difference in differences? Among this set of twins, primary applications fare better than secondary applications in each of the developed countries, with the largest differential in the U.S.

More strikingly, in two of the three countries which have explicit restrictions on secondary patents, there is little evidence that secondary applications fare worse than primary applications do: in India the difference is much smaller than in the developed countries, while in Brazil the primary and secondary grant rates are identical. In Argentina, however, the grant rate for secondary patents remains much lower than that of primaries in this twins sample too, suggesting its policies towards secondary patent applications may be achieving their objectives.

This twins analysis focuses on the smaller number of applications that went national in all PCT countries using the PCT and had an equivalent Argentinian filing. This may also introduce bias, since for applications originating from the U.S. in particular, firms often do not use the PCT to go national, and as result the set of twins in Figures 1(c) and 1(d) does not include many of the US-origin applications (see Table 1 and related discussion). ${ }^{12}$

To eliminate this bias, we can consider only twins filed via PCT in the three developing countries, regardless of how they went national in the developed countries. In India and Brazil almost all applications filed by multinationals go national via PCT, and in Argentina as national equivalents filed after the main application is filed globally. We identified 501 twin applications that were filed in each of these countries. Figure 1(e) and 1(f) show outcomes. Argentina and Brazil have low grant rates for both types of patents, with India considerably higher, and among the three countries only Argentina shows a sharp difference between primary and secondary grant rates. As in all of the analyses above, neither Brazil nor India seem to discriminate much

${ }^{11}$ We find similar results in a regression framework, as reported in the Appendix.

12 This is not an issue in the difference-in-difference analyses over the whole sample reported immediately above. 
between primary and secondary patent applications, suggesting their policies may be having little direct effect.

Limiting the sample to twins filed in all six jurisdictions, or the broader set filed in each of the three developing countries, facilitates cross-country comparison. But there is a trade-off: the applications filed in multiple countries are a select set, so results from this set may be less generalizable. ${ }^{13}$ While this would be a problem if we saw conflicting results, the main results are robust to whether we look at all applications (the most general set, with the largest sample size) and the two sets of twin applications (the most comparable applications, but a select set, with smaller sample sizes). In neither India nor Brazil is there evidence that policies regarding secondary patent matter much (based on raw differences, or differences-in-differences when comparing to other countries without these policies). In Argentina, however, there is evidence more suggestive of effectiveness.

\section{Detailed Analyses of Secondary Patent Prosecution}

Grant rates on secondary patents may be problematic as indicators of the effectiveness of developing country policies. They are driven by other features of national patent systems and based on different sets of national filings. We tried to account for these issues using the difference-in-difference and twins approaches, respectively. A different "bottom up" way to assess the effects of the three developing countries' approaches to secondary patents is to examine the details of patent prosecution. This approach has the advantage of allowing us to see exactly what roles the policy provisions may have had in the prosecution of the applications, and to better understand other influences on national grant rates for secondary patents.

We determined whether applications filed in these three countries were granted, pending, rejected, or abandoned or withdrawn by the applicant. For the rejected Indian applications we determined the grounds cited by the patent office. In particular, we noted whether the specific provision targeting secondary patents, Section 3(d), was cited by examiners, and if so whether it was cited alone or along with other substantive grounds for rejection. For the Brazilian filings, in addition to outcomes at the patent office, we collected information on any role ANVISA had in

${ }^{13}$ To examine how select, we compared the twins to other secondary applications on several dimensions: patent application family size, (the number of countries where the application was filed, from DWPI), the number of claims in the PCT application, PCT filing year, the number of forward citations to the WO application (from DWPI), and whether granted and maintained in the U.S. For the 151 secondary twins-filed in all six countries, family size was the only variable significantly different than those for all other secondary applications (17.4 countries for the twins, 8.2 for the others; $\mathrm{p}<.001$ ). For the 223 twins filed in the three developing countries, the results were similar, with only family size significantly different (17.1 vs. 8.02; $\mathrm{p}<.001)$. Unsurprisingly the twin applications were thus filed more broadly, but do not appear that different based other observable characteristics. However, for some of the measures (forward cites, and share granted and maintained in US) the twins do appear slightly more "valuable" (even if the difference is not significant at conventional levels). Of course it is also possible that they are different on unobservables, which is why it is important to interpret results from these analyses together with those from the other complementary approaches. 
the examination process. For applications filed in Argentina, we looked specifically at applications for "second uses," prohibited as of 2002, and distinguished between those examined before and after the patent office's more restrictive guidelines were introduced in $2012 .^{14}$

Figure 4(a) shows detailed outcomes for secondary applications in India. The grant rate is 40 percent, similar to what we saw above. A small share ( 5 percent) remains pending in India. Roughly 27 percent were withdrawn or abandoned before examination. For these applications, prosecution could not directly have been affected by Section 3(d). Of the 194 applications that the Indian Patent Office rejected, roughly 28 percent of the full set, nearly three quarters of these did not make any mention of 3(d). Instead, these applications were rejected typically for failing to satisfy conventional patentability grounds, such as novelty and inventive step. Forty-eight applications ( 7 percent of the full set, one quarter of the rejected applications) were rejected on grounds including Section 3(d), though the reasons cited for rejection in nearly all of these cases included conventional patentability grounds too. Thus there is reason to believe that these applications may have been rejected even in the absence of Section 3(d). Only two applications for secondary patents were rejected solely on 3(d) grounds. These data do more than reinforce our previous findings that 3(d)'s contribution to the overall outcomes for secondary patents filed in India is less substantial than many expect; they also suggest that, even for rejected applications, 3(d) plays a small independent role.

- Figure $4-$

Figure 4(b) shows detailed outcomes in Brazil. As all of the cross-national analyses have revealed, Brazil has a low grant rate: only 5 percent of applications for secondary patents in Brazil were granted. Eleven percent of the applications remain pending in Brazil, reflecting the country's substantial backlog. The modal outcome in Brazil is withdrawal before the completion of examination, an outcome experienced by nearly 60 percent of the applications. Applications in Brazil are withdrawn overwhelmingly because the applicant stopped paying fees, before the application underwent substantive examination. Withdrawal, and not rejection, is the main explanation for Brazil's low grant rate.

Prior Consent rejections are rare: only 19 of the secondary applications (10 percent of rejected applications, and 2 percent of the full set) were rejected after being handled by ANVISA. Moreover, since we code Prior Consent rejections liberally, including in this category any

${ }^{14}$ Our analyses are based on all national phase applications filed in each country that emanate from our original set of PCT applications, and that some PCTs have multiple national phase applications. From the 2,964 secondary PCT applications in our sample, this approach yields 697 applications in India, 972 in Brazil, and 533 in Argentina. While we calculated grant rates above based on whether any of the national applications were granted, here we examine outcomes for all national phase applications, since we are calculating a range of outcomes (beyond whether "any national phase granted") that may vary within individual PCT applications. For example, if one PCT was linked to four national phase applications in a country, in the earlier analyses we classified the PCT as granted in the country if any of the four applications were granted, while here we treat each of the four as discrete applications with their own outcomes. 
application that was seen by ANVISA that was later rejected by INPI or withdrawn, these figures actually overstate the role of the patent examiners in the health agency. Of the 19 Prior Consent rejections, only four were under the old workflow, where the application was first approved by INPI before being reviewed by ANVISA. Of the remaining 15 under the new workflow, where applications go to ANVISA first, only one was denied consent by ANVISA. ${ }^{15}$ In sum, looking at the entirety of secondary applications filed in Brazil in our dataset, in only one half of one percent of these (5 of 972) did an application end up either rejected or withdrawn following ANVISA's denial of consent.

Figure 4(c) shows detailed outcomes for Argentina. As in Brazil the grant rate is low, at just 7 percent. The rejection rate is low, too, at roughly 10 percent. Here too, in fact more than in the other countries, withdrawal before substantive examination is the dominant outcome.

Unlike 3(d) and Prior Consent, which target broad classes of secondary patents, the Argentinian policy during most of the period under study focused on one type of secondary patent: second uses. Unfortunately we do not have information on specific grounds for rejection in Argentina, so our ability to evaluate the role of this specific provision is limited. However, our application codings (see Appendix) allow us to identify applications that only have use claims. None of the 73 pure use applications filed in Argentina were granted, suggesting that the 2002 restriction was effective. However, since pure use applications account for only 15 percent of the secondary applications in Argentina the specific provisions cannot be the main explanation for the low grant rate. ${ }^{16}$

What about the new, more restrictive examination guidelines effective introduced in 2012, which target a broader range of secondary patents? Of the 533 secondary applications filed in Argentina, 137 were examined under the new guidelines. The grant rate for secondary patent applications fell from 9 percent to less than 1 percent after the new guidelines. While in part this reflects censoring (newer applications are more likely to be pending) it is notable that the grant rate for primary applications fell by much less, from 14 to 10 percent. This suggests the new guidelines may be having an effect as well. But since only a quarter of the secondary applications in our sample were examined after the new guidelines were introduced, they cannot be the main explanation for Argentina's low grant rate either.

A salient feature in each country is withdrawal of applications before substantive examination. In a final set of analyses, focusing on secondary applications that were withdrawn in India, Brazil, and Argentina, we determined U.S. status of the matched twin application (for the applications that had national phase filings in the U.S.). As Figure 5 shows, in each country withdrawn applications are disproportionately those that did not get granted in the U.S. or were granted and

${ }^{15}$ Of the remaining applications, some received ANVISA's consent but were later rejected by INPI or withdrawn, and some were withdrawn before ANVISA could make a judgement.

${ }^{16}$ It is possible that the provision was used to remove pure use claims from patents whose other claims were granted. In Argentina, as in the other countries, we cannot example claim narrowing with the data currently available, but hope to look at this in future research. 
not renewed: 78 percent in India, 84 percent in Brazil, and 76 percent in Argentina. Given the preponderance of withdrawn applications among the non-grants in these countries, particularly in Argentina and Brazil, this suggests that an important feature of the grant rate for secondary patents in developing countries is learning that applications are not successful or worth pursuing even in the U.S. The lag between global filing and examination in the developing countries may serve as a filter, a point to which we return below. ${ }^{17}$

- Figure 5 -

\section{Discussion}

The data reveal considerable heterogeneity in cross-national grant rates on secondary patents. The U.S. and European patent offices have the highest grant rates. Brazil and Argentina have the lowest grant rates, Japan and India are in the middle. This clustering is consistent throughout all of the analyses, looking at the full set of secondary applications, at segments stratified according to various measures of importance, and the twin applications filed in all six countries.

The primary aim of the analyses was to assess the effectiveness of developing countries' specific instruments to restrict secondary patents. Evidence from both the comparative grant rates and detailed analyses of patent prosecution points to the limited direct effects of these measures in India and Brazil.

However, the explanations for why Section 3(d) and Prior Consent are having only small direct roles may be different in the two countries. In India, both the lack of difference in primary-secondary grant rates, and the low utilization of pure 3(d) rejection are consistent with a standard account of institutional weakness in developing countries: formal rules are often not consistently enforced (Levitsky and Murillo 2009). The patent office operates under severe resource constraints, and is faced with the challenge of working through substantial quantities of applications on new, previously unpatentable subject matter. Moreover, India's patent examiners are tied into global networks, through training and via reliance on foreign databases and prosecution materials (Kapcyznksi 2009; Drahos 2010; Sampat and Amin 2013). Such conditions, may limit the extent to which examiners employ Section 3(d) in the course of evaluating pharmaceutical patent applications.

Another explanation for the limited role played by Section 3(d) might be that the scope for independent action of this provision may be constrained. Nearly all rejections in our dataset that cited Section 3(d) also gave other grounds for denying the patents. Although Section 3(d) was involved in these rejections, this specific provision may not have been needed to reject these

\footnotetext{
${ }^{17}$ Since Japan has a formal deferred examination system applications there may also benefit from post-application learning (Yamauchi and Nagaoka 2015). Consistent with this, of those granted and renewed in the U.S. 70 percent are granted in Japan, compared to just 28 percent of those granted but not renewed in the U.S. This suggests that the high non-grant rate in Japan too may reflect withdrawal of applications deemed no longer worth pursuing, though absent detailed outcome data in Japan it is difficult to test this directly.
} 
applications, which were rejected on other grounds too. To the extent that 3(d) is similar, in terms of the sorts of applications it is used to reject, to conventional patentability criteria, such as lack of novelty or inventive step, then the limited role played by 3(d) per se becomes less surprising. ${ }^{18}$

Brazil's measures to restrict secondary patenting also appear to have had a limited direct effect. Though Brazil has a low grant rate, the differences between primary and secondary grant rates are indistinguishable, and our detailed analyses revealed negligible involvement by ANVISA. Difficulties of inter-agency coordination, often cited as a factor complicating enforcement (e.g. Dimitrov 2009) could provide one explanation for this surprising finding. The Prior Consent system relies on the participation of two separate state agencies, and disagreements between INPI and ANVISA over Brazil's approach to pharmaceutical patents have been intense (Shadlen 2011; Kunisawa 2009). However, these disagreements and conflicts cannot account for the finding the finding that the effects of ANVISA on patenting outcomes are so small. Examination in Brazil is sequential, not simultaneous; minimal coordination is required. For most of applications in our dataset, prosecuted under the old workflow, all the work was done by INPI itself. Few of these applications ever cleared the first hurdle at INPI to be passed to ANVISA, but rather they were rejected or withdrawn while still at the patent office. For reasons explained above, the backlog at the patent office seems like a better explanation of limited role of ANVISA than problems with inter-agency coordination. ${ }^{19}$

In Argentina, unlike in either of the other developing countries, we do see differences in primary-secondary grant rates. The analyses of prosecution details also suggest that both the prohibitions on second use patents and the more restrictive examination guidelines that came into place in 2012 may be having their intended impact. One explanation for this is that Argentina's approach is comparatively easier to employ. It does not rely on application of a different sort of patentability criteria (as in India) or the participation of multiple agencies (as in Brazil), but simply constitutes instructions to patent examiners for how to go about rejecting secondary patents using traditional patentability criteria (e.g. lack of novelty or inventive step).

However effective Argentina's policies toward secondary patents may have been, since only a minority of the applications in our dataset was subject to these measures they cannot explain the whole story. As in Brazil, one explanation for the low overall grant rate seems to be slow prosecution and applicants' decisions to give up on applicants they deem to be less important. In Argentina this effect may be bolstered by a policy aimed specifically at clearing the backlog. The patent office often issues requirements that applicants report on the status of applications filed abroad. If firms fail to respond, the pending applications are converted to abandoned or withdrawn.

18 This explanation would raise the broader question about why $3(\mathrm{~d})$ is so controversial if its scope is small.

${ }^{19}$ Now that ANVISA sees applications first, under the new workflow, it will become more involved. It is important to keep in mind the important difference in the pool of applications ANVISA would have seen under the old workflow (applications approved by INPI) and under the new workflow (all applications for pharmaceutical patents). 
Another part of the story in Argentina is that, even before the new guidelines formally came into place they may have informed examiner practice. That is, the official establishment of new guidelines in 2012 may have reflected a new approach to examination that had already been adopted. Whereas in India and Brazil laws on the books have had limited direct impacts on patent prosecution in practice, in Argentina changes in patent prosecution in practice may have later been codified in laws on the books.

\section{Conclusion}

In this paper we used novel data on a large sample of filings emanating from PCT applications in three developed countries and three developing countries with restrictions on secondary patenting. We coded the applications as secondary (or primary) and identified a large set of "twin" filings across multiple jurisdictions to compare grant rates and evaluate restrictions toward secondary patents. We also examined the details of patent prosecution in the three developing countries to better understand the role of specific arrangements toward secondary patents, alone and in comparison to other influences on patenting outcomes.

We found considerable differences in cross-national grant rates for secondary patents, despite the harmonization aimed for by TRIPS. Conditional upon filing, grant rates for secondary patents in the six countries ranged from 5 percent (Brazil) to 52 percent (U.S.). In all countries grant rates are higher for applications filed more broadly and (in all countries but the U.S.) for applications more vigorously pursued in the U.S., indicating grant rates reflect the extent of applicant effort in pursuing the applications. But even for these more important applications, differences in grant rates of secondary patents persist. These findings suggest that more attention be paid to differences in countries' pharmaceutical patent systems, to look "inside the black box" of patent examination to try to understand how countries' patent systems function in practice.

We did not find much evidence that developing countries' policies to restrict secondary patents are driving outcomes. In the case of two countries, India and Brazil, the policies seem to be having little effect at all: grant rates for secondary patents are not lower than grant rates for primary patents in these countries, which they should be if policies designed specifically to achieve that outcome were working, and the detailed analyses of patent prosecution also reveal Section 3(d) and Prior Consent to be playing only limited direct roles. Argentina's measures to restrict secondary patents appear to be more effective: grant rates for secondary patents are considerably lower than those for primary patents, patents on second medical use are not granted, and the secondary patent grant rate following the introduction of the new guidelines has further declined. But the overall impact on secondary patenting outcomes of Argentina's measures is small: the bulk of applications in our sample (pre-2012, non-use applications) were not subject to either the prohibition on second use patents or the new examination guidelines.

The detailed analyses also illustrated the potentially important role of other features of countries' patent systems. In all three countries large backlogs of applications and timing of TRIPS implementation contribute to delays in initiating examination, so that it often does not begin until information from developed country offices has become available. In this context, if resource-contained patent offices were inclined to rubber stamp developed country actions, as 
some previous analysts have suggested (Drahos 2010), this would lead to high grant rates for secondary applications. But our analyses suggests another effect of the backlog: the delays they introduce may serve as a filter, leading firms to abandon less important applications based on information from other countries. That is, they may unintentionally mimic features of deferred examination systems, leading to lower grant rates.

One implication of our analyses is thus that administrative and procedural features of patent systems may play important roles in patent prosecution, and may actually exert a greater influence on grant rates than laws on the books per se. Although this is consistent with recent work on the USPTO (Lemley and Sampat 2012; Frakes and Wasserman forthcoming), since this was not the main focus of our research, more work is needed to examine exactly how these features influence outcomes in developing countries.

While we found minimal direct effects of countries' provisions toward secondary patents, there may be more indirect effects that our data do not capture. In India, it is possible that 3(d) influences prosecution by affecting how examiners apply other aspects of the patent law. That is, Section 3(d) might alter Indian patent examiners' overall approach to assessing applications and using conventional patentability criteria, such that applications rejected on grounds above and beyond 3(d) might not be rejected at all if not for this distinct provision in Indian patent law. And in Brazil, prior to the introduction of the new workflow in 2012, it is possible that ANVISA's participation in examination may have created incentives for rejection at the patent office. INPI examiners knew that favorable decisions would subsequently be scrutinized by counterparts at ANVISA while rejections and other applications without a decision would not be.

Another potential indirect effect is on selective filing. We believe this is likely limited given the timing of when the applications were filed and when the policies were introduced. A similar possibility is selective withdrawal of secondary applications in response to countries' policies toward these types of applications, though we showed above that most withdrawal in India, Brazil, and Argentina is for applications that were revealed to be not worth renewing even in the U.S. While we do not view this particular indirect effect as being important, we cannot rule it out completely.

There are other limitations as well. While our analysis focuses on grant rates, it is possible that the main impact of the provisions is on narrowing claims in granted patents, or that the provisions matter most for specific kinds of secondary patents. It is also likely that there are changes over time. Our research focuses on applications filed from 2000-2002, for reasons discussed. But as with all policies it is possible that there are implementation lags, and that countries' measures to restrict secondary patents matter more for more recently filed applications. Another limitation, reflecting the difficulty of obtaining reliable data on patent prosecution in developing countries, is that we focus on a relatively small set of developing countries. Extending to a broader set of comparable countries, including those without restrictions is also a promising avenue for future research.

The universalization of pharmaceutical patenting through TRIPS generated significant controversy. The spread of secondary patenting has been the subject of particular concern among 
academics, activists, and policymakers, based on fears that such patents may restrict competition and thus inhibit access to medicines. Despite the attention that secondary patenting has received, we know little about what is happening on the ground. Our analyses provide the first cross-national comparative data on secondary patent grant rates, and on the actual impact of policies aiming to restrict them in developing countries. They reveal surprising but robust patterns of cross-national differences in grant rates. Subject to the limitations listed above, the analyses also suggest that the restrictions in developing countries are having limited direct effect. From a methodological perspective, they also point to the benefits of combining application-level analyses with prosecution details to understand the functioning of patent systems and the impact of patent policies.

\section{References}

Abud, M.J., Hall, B., Helmers, C., 2015. An Empirical Analysis of Primary and Secondary Pharmaceutical Patents in Chile. PLoS ONE 10, e0124257. doi:10.1371/journal.pone.0124257

Amin, T., Kesselheim, A.S., 2012. Secondary patenting of branded pharmaceuticals: a case study of how patents on two HIV drugs could be extended for decades. Health Aff (Millwood) 31, 2286-2294. doi:10.1377/hlthaff.2012.0107

Basheer, S., Reddy, P., 2008. The "Efficacy" of Indian Patent Law: Ironing out the Creases in Section 3(d) (SSRN Scholarly Paper No. ID 1086254). Social Science Research Network, Rochester, NY.

Barbosa, D.B. 2013. Patents and the Emerging Markets of Latin America: Brazil. In Emerging Markets and the World Patent Order, edited by Frederick M. Abbott, Carlos M. Correa, and Peter Drahos, 135-51. Edward Elgar Publishing.

Basso, M., 2006. Intervention of health authorities in patent examination: the Brazilian practice of the prior consent. International Journal of Intellectual Property Management 1, 54-74.

doi:10.1504/IJIPM.2006.011022

Berndt, E.R., Cockburn, I.M., 2014. The Hidden Cost Of Low Prices: Limited Access To New Drugs In India. Health Aff 33, 1567-1575. doi:10.1377/hlthaff.2013.130

Burdon, M., Sloper, K., 2003. The art of using secondary patents to improve protection. J. Med. Mark. 3, 226-238. doi:10.1057/palgrave.jmm.5040125

Carley, M., Hedge, D., Marco, A., 2015. What Is the Probability of Receiving a U.S. Patent. Yale J.L. \& Tech. 17, 203. 
Christie, A.F., Dent C., Liddicoat, J. 2016. The Examination Effect: A Comparison of the Outcome of Patent Examination in the US, Europe and Australia. John Marshall Review of Intellectual Property Law 16, 21-43.

Correa, C.M., 2014. Tackling the Proliferation of Patents: How to Avoid Undue Limitations to Competition and the Public Domain (No. Research Paper 52). South Centre.

Correa, C.M., 2007. Guidelines for the Examination of Pharmaceutical Patents: Developing a Public Health Perspective. ICTSD.

Correa, C.M., Balleri, C., Giulietti, M., Lavopa, F., Musetti, C., Palopoli, G., Pippo, T., De la Puente, C., Lowenstein, V., 2011. Patentes, suministro de medicamentos y protección de la Salud Pública; Patents, supply of medicines and protection of public health. Rev. argent. salud publica 2, 19-27.

de Rassenfosse, G., Jaffe, A., Webster, E., 2016. Low-quality Patents in the Eye of the Beholder: Evidence from Multiple Examiners (No. w22244). National Bureau of Economic Research, Cambridge, MA.

Dimitrov, M., 2009. Piracy and the State: The Politics of Intellectual Property Rights in China. Cambridge University Press.

Drahos, P., 2010. The Global Governance of Knowledge: Patent Offices and Their Clients. Cambridge University Press.

Drahos, P., 2008. "Trust Me": Patent Offices in Developing Countries. American Journal of Law \& Medicine 34, 151.

Duggan, M., Garthwaite, C., Goyal, A., 2016. The Market Impacts of Pharmaceutical Product Patents in Developing Countries: Evidence from India $\uparrow$. American Economic Review 106, 99-135. doi:10.1257/aer.20141301

Dutfield, G., Suthersanen, U., 2005. Harmonisation or differentiation in intellectual property protection? The lessons of history. Prometheus 23, 131-147. doi:10.1080/08109020500085528

Eisenberg, R.S., 2008. Pharma's Nonobvious Problem. Lewis \& Clark L. Rev, Articles 12, 375-430.

Ellery, T. Hansen, N. 2012. Pharmaceutical Lifecycle Management: Making the Most of Each and Every Brand. Wiley.

European Commission, 2009. Pharmaceutical Sector Inquiry Report.

Frakes, M., Wasserman, M., forthcoming. Is the Time Allocated to Review Patent Applications Inducing Examiners to Grant Invalid Patents?: Evidence from Micro-Level Application Data. Review of Economics and Statistics. 
GAO, 2016. Patent Office Should Define Quality, Reassess Incentives, and Improve Clarity (No. GAO-16-490). Government Accountability Office, Washington, D.C.

Hemphill, C.S., Sampat, B.N., 2011. When Do Generics Challenge Drug Patents? Journal of Empirical Legal Studies 8, 613-649. doi:10.1111/j.1740-1461.2011.01235.x

Hopkins, M.M., Mahdi, S., Patel, P., Thomas, S.M., 2007. DNA patenting: the end of an era? Nature Biotechnology 25, 185-187. doi:10.1038/nbt0207-185

Howard, L., 2007. Use of Patents in Drug Lifecycle Management. Journal of Generic Medicines 4, 230-236. doi:10.1057/palgrave.jgm.4950065

Jaffe, A.B., Lerner, J., 2004. Innovation and Its Discontents: How Our Broken Patent System is Endangering Innovation and Progress, and What to Do About It. Princeton University Press.

Jensen, P.H., Palangkaraya, A., Webster, E., 2006. Disharmony in international patent office decisions. Federal Circuit Bar Journal 15, 679-704.

Kapczynski, A., 2013. Engineered in India: Patent Law 2.0. New England Journal of Medicine 369, 2163-2163. doi:10.1056/NEJMc1311602

Kapczynski, A., 2009. Harmonization and its Discontents: A Case Study of TRIPS Implementation in India's Pharmaceutical Sector. California Law Review 97, 1571-1649.

Kapczynski, A., Park, C., Sampat, B., 2012. Polymorphs and Prodrugs and Salts (Oh My!): An Empirical Analysis of "Secondary" Pharmaceutical Patents. PLoS ONE 7, e49470. doi:10.1371/journal.pone.0049470

Kesselheim, A.S., 2007. Intellectual property policy in the pharmaceutical sciences: The effect of inappropriate patents and market exclusivity extensions on the health care system. The AAPS Journal 9, E306-E311. doi:10.1208/aapsj0903033

Kunisawa, V.Y.M., 2009. Patenting Pharmaceutical Inventions on Second Medical Uses in Brazil. The Journal of World Intellectual Property 12, 297-316. doi:10.1111/j.1747-1796.2009.00362.x

Lanjouw, J.O., Pakes, A., Putnam, J., 1998. How to Count Patents and Value Intellectual Property: The Uses of Patent Renewal and Application Data. The Journal of Industrial Economics 46, 405-432. doi:10.1111/1467-6451.00081

Lemley, M.A., Moore, K.A., 2004. Ending Abuse of Patent Continuations. Boston University Law Review 84, 63-118. doi:10.2139/ssrn.462404

Lemley, M.A., Sampat, B., 2012. Examiner Characteristics and Patent Office Outcomes. Review of Economics and Statistics 94, 817-827.doi:10.1162/REST_a_00194

Lemley, M., Sampat, B.N., 2008. Is the Patent Office a Rubber Stamp? Emory Law Journal 58, 181 -. 
Lerner, J., 2000. 150 Years of Patent Protection (Working Paper No. 7478). National Bureau of Economic Research.

Levitsky, S., Murillo, M.V., 2009. Variation in Institutional Strength. Annual Review of Political Science 12, 115-133. doi:10.1146/annurev.polisci.11.091106.121756

Löfgren, H., Williams, O.D., 2013. The New Political Economy of Pharmaceuticals: Production, Innnovation and TRIPS in the Global South. Palgrave Macmillan.

Maskus, K.E., 2000. Intellectual Property Rights in the Global Economy. Institute for International Economics, Washington, DC.

Moir, H.V.J., 2013. Empirical Evidence on the Inventive Step. European Intellectual Property Review $35,246-252$.

PhRMA. 2016. Special 301 Submission 2016.

http://phrma-docs.phrma.org/files/dmfile/special-301-review.pdf

Rathod, S.K. 2010. Ever-Greening: A Status Check in Selected Countries. Journal of Generic Medicines 7, 227-242.

Reichman, J.H., 2009. Intellectual Property in the Twenty-First Century: Will the Developing Countries Lead or Follow? Houston Law Review 46, 1115-1185.

Sampat, B.N., Amin, T., 2013. How Do Public Health Safeguards in Indian Patent Law Affect Pharmaceutical Patenting in Practice? Journal of Health Politics, Policy, and Law 38, 735-55.

Sampat, B.N., Shadlen, K.C., 2015a. Drug patenting in India: looking back and looking forward. Nature Reviews Drug Discovery 14, 519-520.

Sampat, B.N., Shadlen, K.C., 2015b. TRIPS Implementation and Secondary Pharmaceutical Patenting in Brazil and India. St Comp Int Dev 50, 228-257. doi:10.1007/s12116-015-9181-7

Shadlen, K.C., 2011. The Political Contradictions of Incremental Innovation: Lessons from Pharmaceutical Patent Examination in Brazil. Politics \& Society 39, 143-174. doi:10.1177/0032329211402601

Schultz, M. and Madigan, K. 2016. "The Long Wait for Innovation: The Global Patent Pendency Problem." Center for the Protection of Intellectual Property. http://cpip.gmu.edu/wp-content/uploads/2016/10/Schultz-Madigan-The-Long-Wait-for-Innovatio n-The-Global-Patent-Pendency-Problem.pdf

Silva, H.M., 2008. Avaliação da análise dos pedidos de patentes farmacêuticas feita pela Anvisa no cumprimento do mandato legal da anuência prévia. ENSP, Rio de Janeiro. 
South Centre, 2011. The Doha Declaration on TRIPS and Public Health Ten Years Later: The State of ImplementationPolicy Brief 7, November 2011.

Sternitzke, C., 2010. Knowledge sources, patent protection, and commercialization of pharmaceutical innovations. Research Policy 39, 810-821. doi:10.1016/j.respol.2010.03.001

UNAIDS, 2011. Doha+10 TRIPS flexibilities and access to antiretroviral therapy: Lessons from the past, opportunities for the future.

USPTO, 2015. Maintenance Fee Register. https://www.google.com/googlebooks/uspto-patents-maintenance-fees.html\#1981-present

USTR, n.d. Special 301 [WWW Document]. URL https://ustr.gov/issue-areas/intellectual-property/Special-301 (accessed 7.28.16).

Webster, E., Jensen, P.H., Palangkaraya, A., 2014. Patent examination outcomes and the national treatment principle. The RAND Journal of Economics 45, 449-469. doi:10.1111/1756-2171.12053

Yamauchi, I. and Nagaoka, S. 2015. An Economic Analysis of Deferred Examination System: Evidence from a Policy Reform in Japan. International Journal of Industrial Organization 39: 19-28. doi:10.1016/j.ijindorg.2015.01.003. 


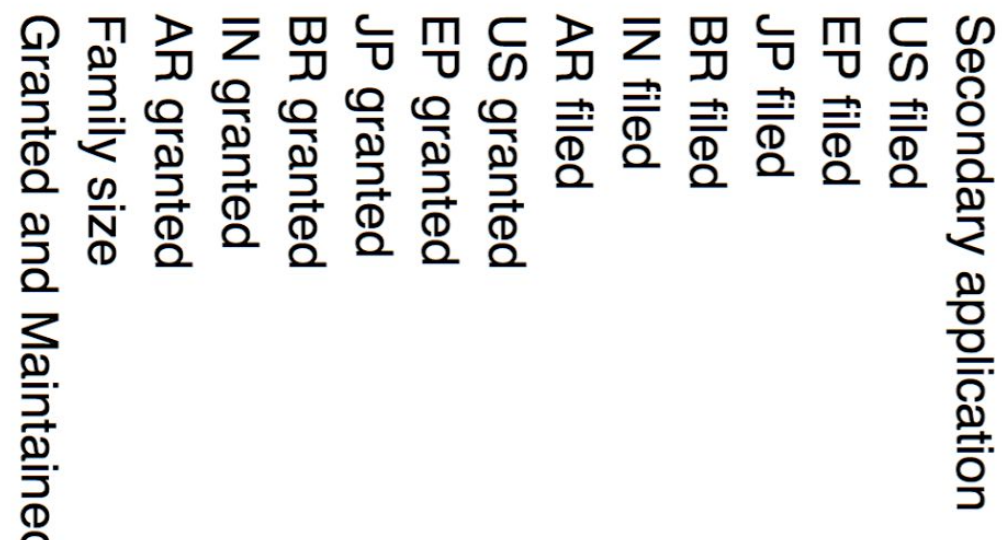

ㅇ.

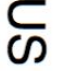

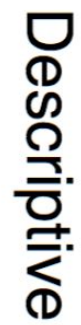

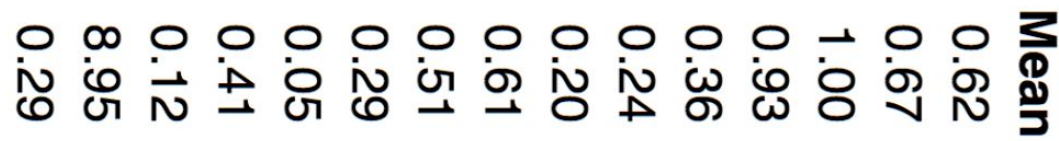

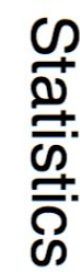

$000000000000000 \frac{3}{3}$

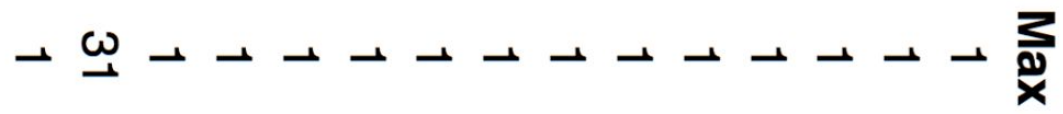

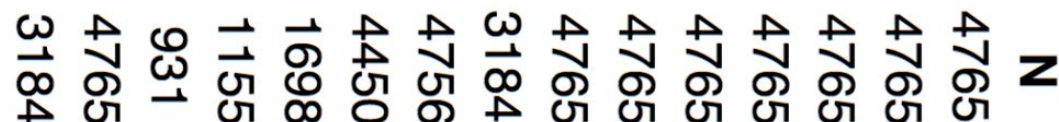




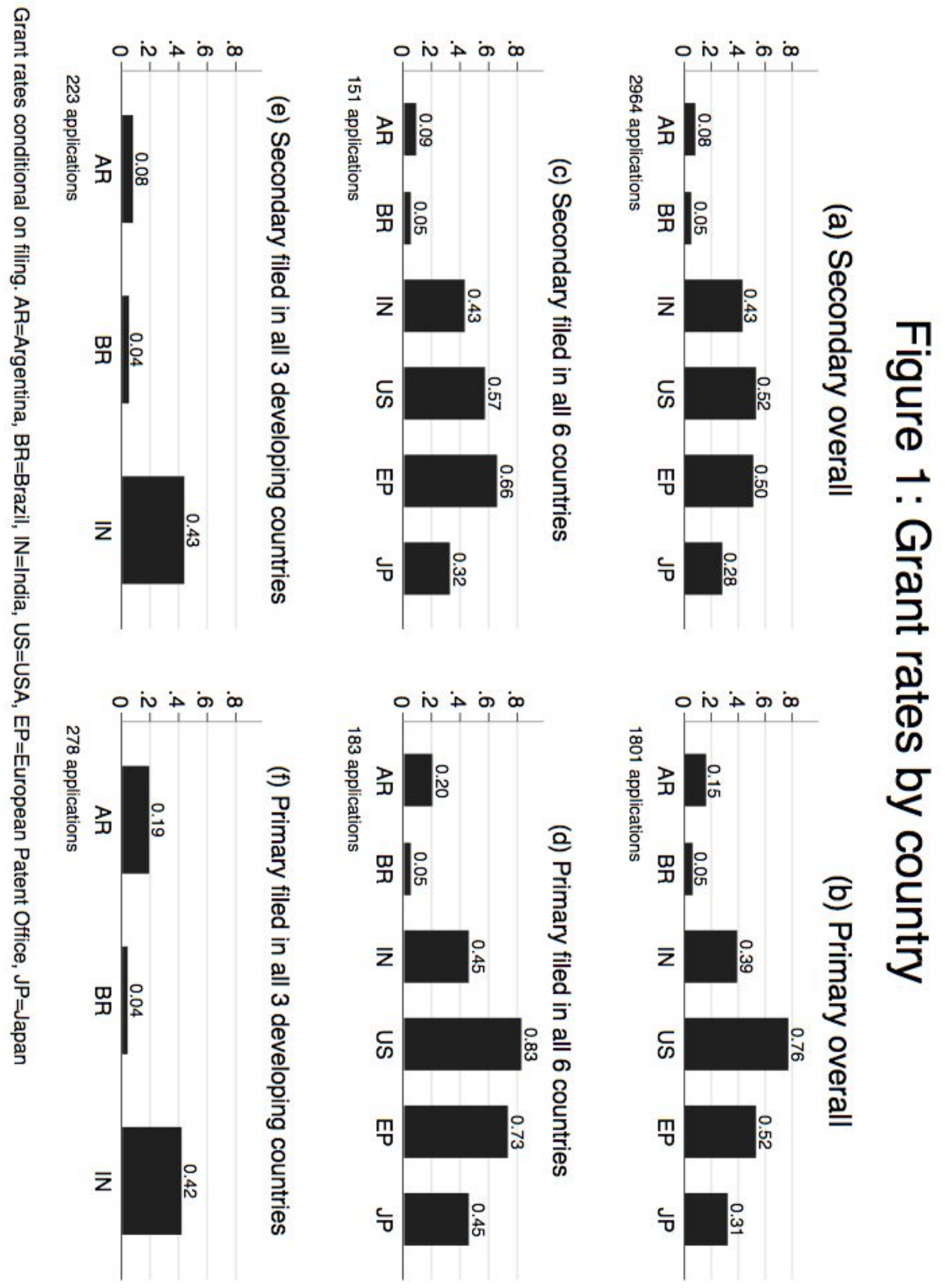



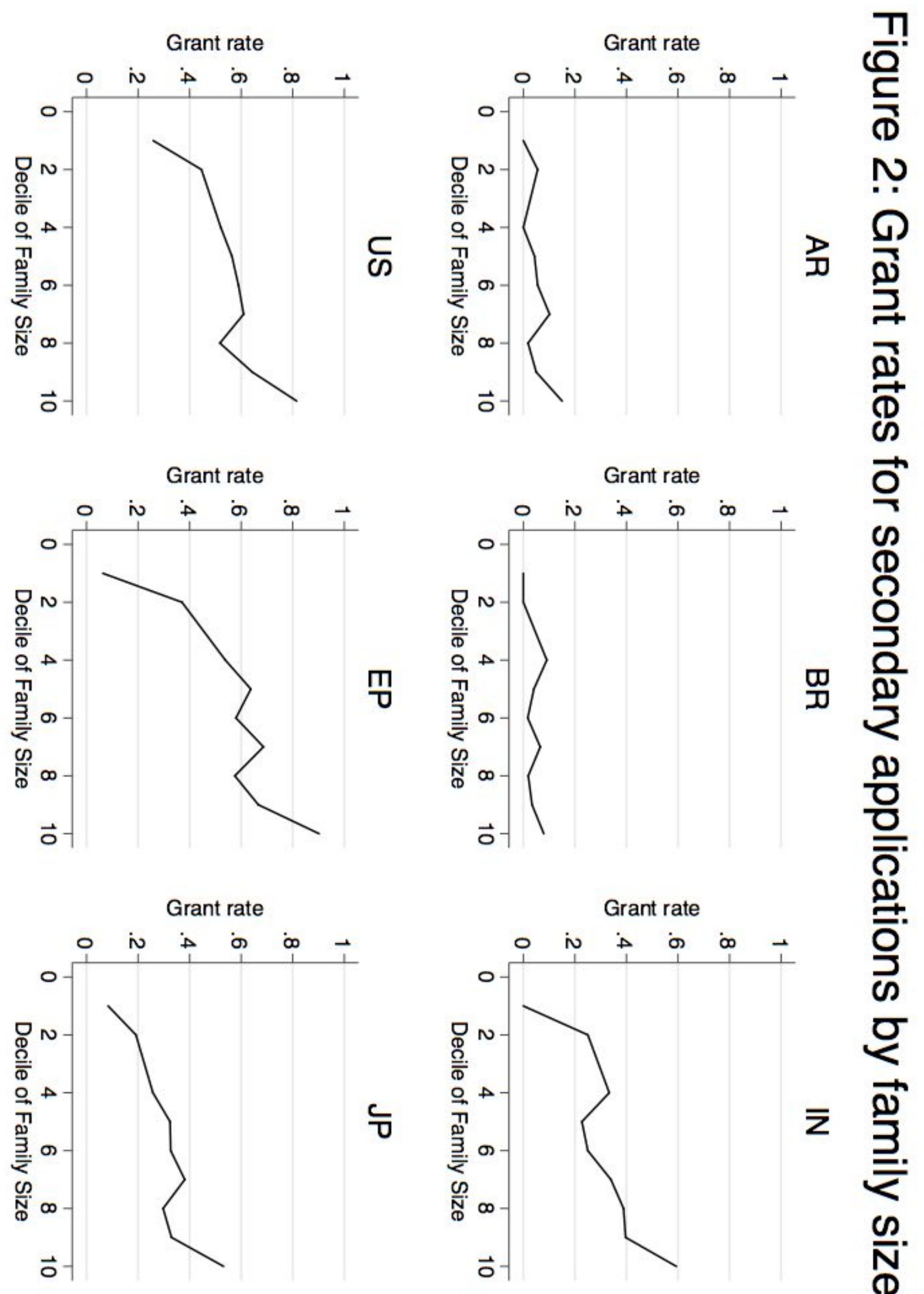

m

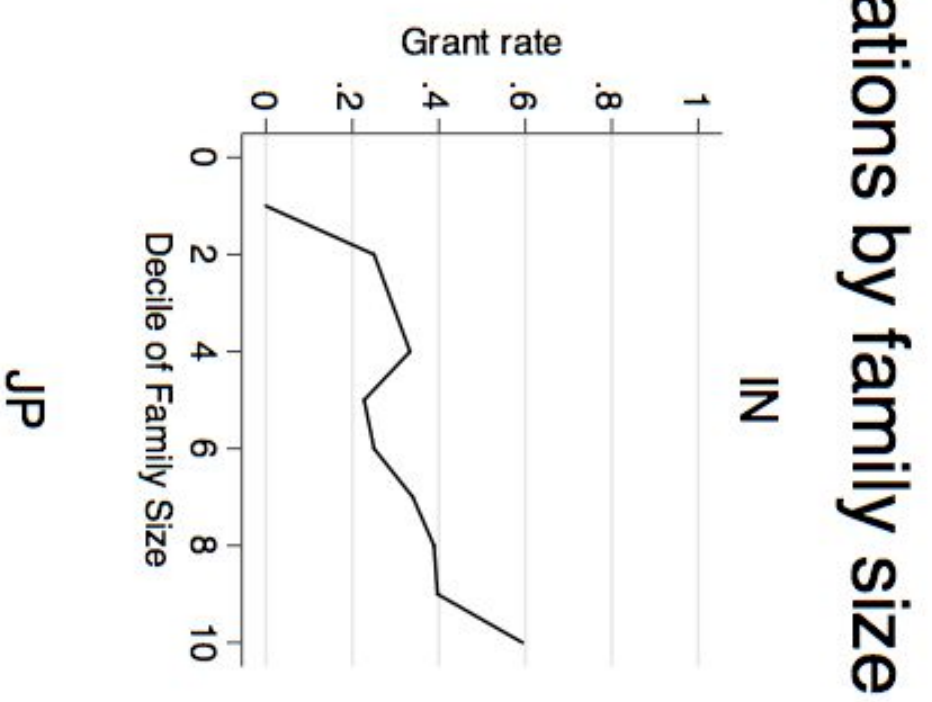




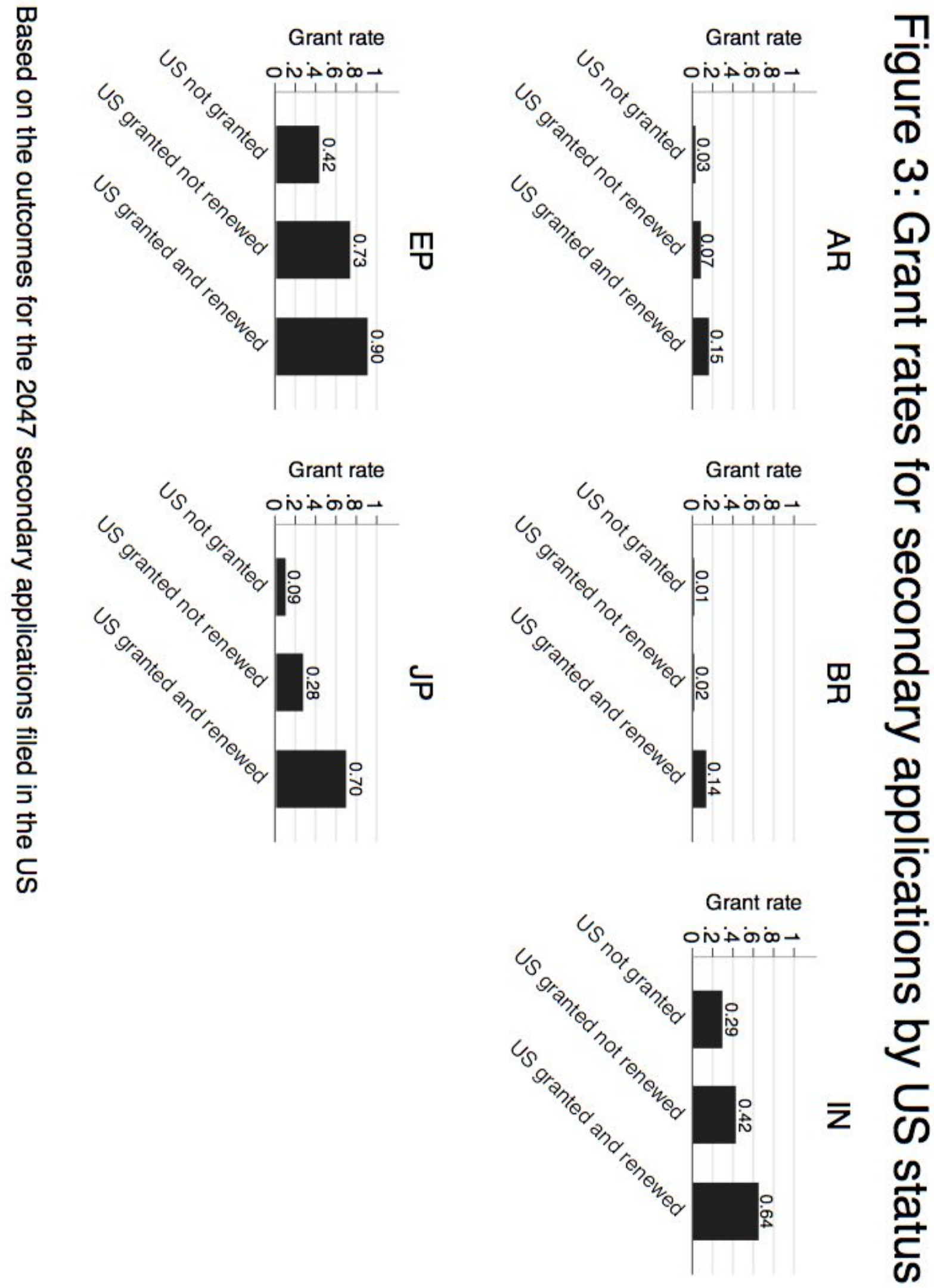




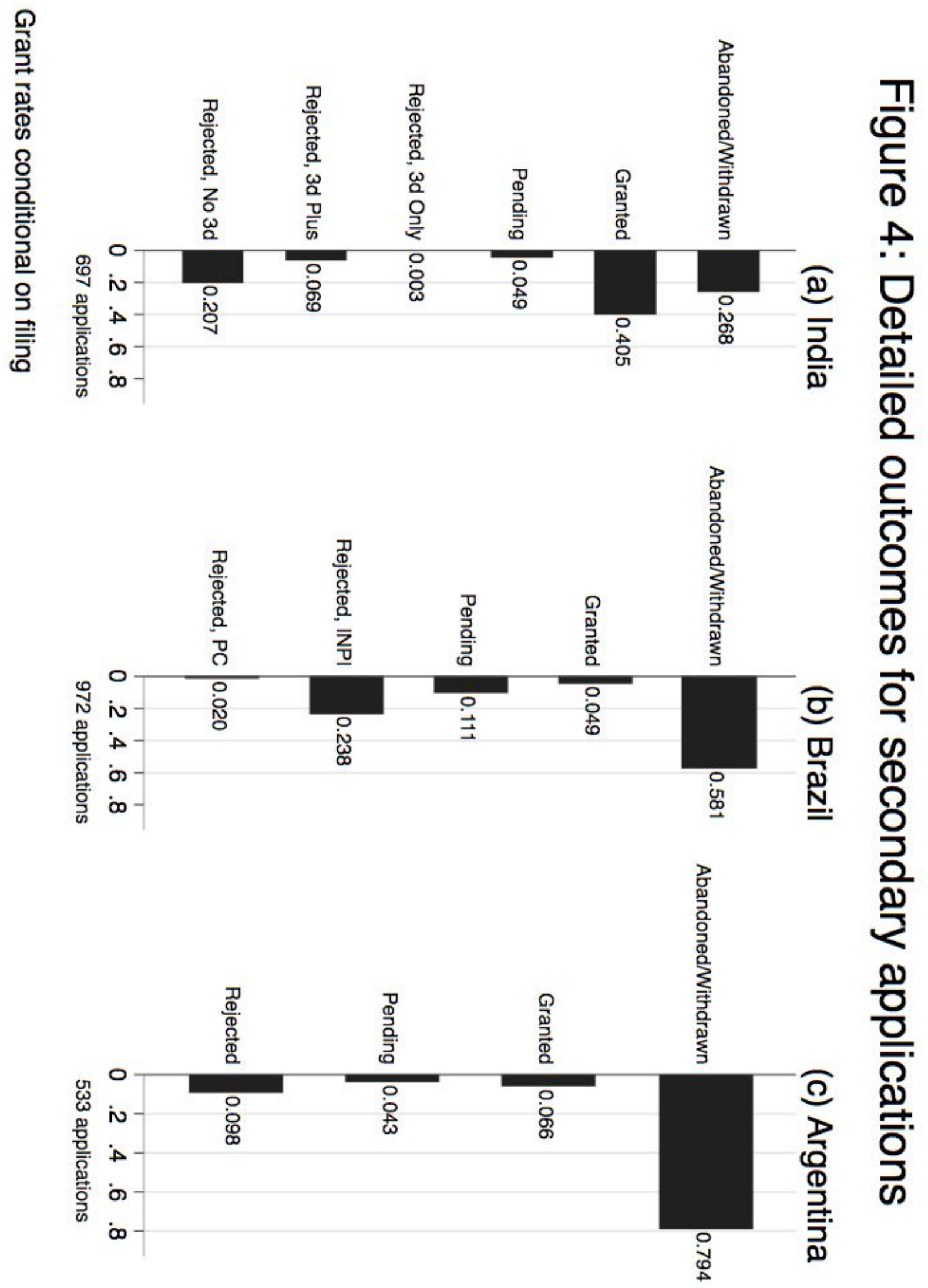



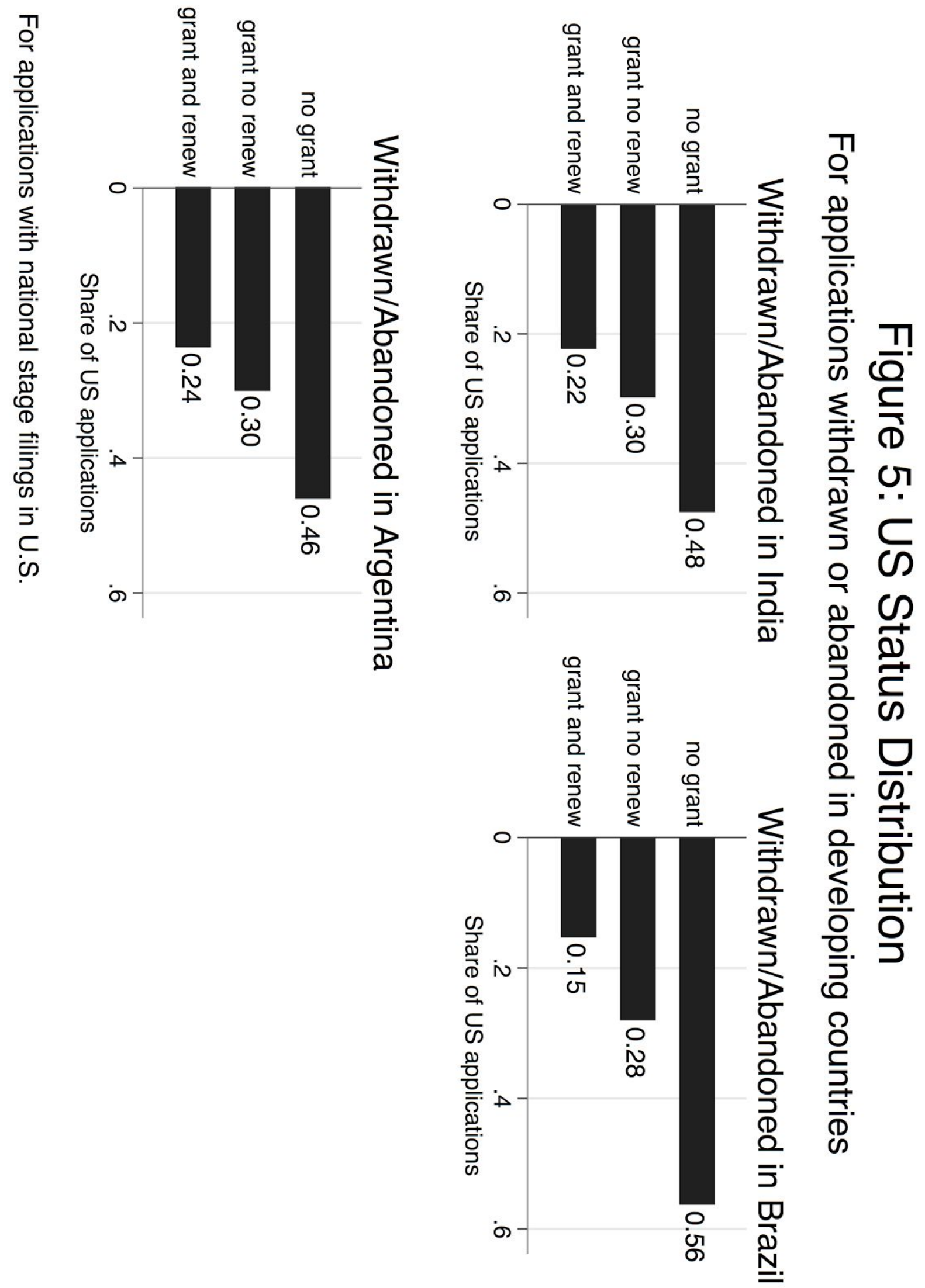


\section{Appendix}

\section{Coding Guide}

A coding guide was provided to the coder to categorize the 5,193 PCT applications. It is adapted from a guide designed by Scott Hemphill that was used to code US patent grants (Hemphill and Sampat 2011). Below, we excerpt the first page of the coding guide.

General: We want to code the information in the published application (the WO document). To do so, click through the link provided for each application, which will take you to the Google transcription of the application. (This is useful since Google typically does translation for us, and the layout is pretty clean.) If you need the actual PDF file, you can access it through the PatentScope and/or Espacenet links provided in the Google patent file. We anticipate you will use information in the independent and dependent claims for the coding, supplemented by information in the title, abstract, description as needed. If you use any information beyond this please indicate this in the notes field.

Coding: Our main goal is to code applications by type. There are five broad categories of claims. A patent can, and often does, include more than one category of claims:

- A: active ingredient (see specific descriptions of A1-A4 below)

- B: formulation or composition

- C: method of use

- D: other, but related to the drug

- E: biologic

For each patent, indicate all categories that apply to a patent. For active ingredient claims, we want to distinguish the four subcategories:

- A1: active ingredient.

- A2: is for polymorphs or other crystal forms.

- A3: is for enantiomers or other isomers.

- A4: salt, metabolite, or intermediate. Also pre-metabolites and derivatives

\section{Identifying National Phase Application Numbers and Outcomes}

\section{$E P O, J P O$, and US}

We obtained EPO, JPO, and US national phase numbers from the WIPO Statistical Database, the same source we used to construct the basic dataset.

We also obtained outcomes data from PATSTAT. For a random sample of 100 applications, we verified these sources provided essentially identical grant rate information as was determinable from the EP Register, the JPO Website, and USPTO Public PAIR. The U.S. grant rate calculated from PATSTAT is based on all grants from a given priority, so includes grants to all "child" applications (continuations) which we also verified against PAIR.

\section{India}

We obtained national phase applications in India from PatentScope, and Indian outcomes from the IPO Website. Any granted application was classified as Granted. We considered an Indian application to be Abandoned/Withdrawn if the status on the IPO website is withdrawn without stated reason, or withdrawn under 11(B)4. Section 11(B)4 withdrawals are those where no request 
for examination was made. Given the time elapsed since filing, we assume that applications "Not Yet Published" were withdrawn before examination. We also grouped Section 9(1) Abandonments as withdrawals: these are cases where a complete specification was not filed.

We classify applications as Rejected if they were abandoned under Section 21(1). Section 21(1) abandonments are typically those where there was a failure to respond to objections in a FER within the time limits prescribed. Our logic here is that these applications were abandoned because of the examiner's objections. It is also possible that the lack of response was for other reasons (e.g. the firm went out of business, the technology no longer interesting to the firm, or problems with the application were discovered at another patent office). Accordingly our analysis overstates rejection rates. Refusals through Controller decisions (including those indicated as Section 15 and 16 rejections) were also classified as rejections. Refusals through Controller Decisions result when a controller is unsatisfied with an applicant's response to the FER and/or the Controller refuses an application where there is a pre-grant opposition. As discussed more below, we focus on these Rejected cases when we examine how 3(d) is affecting rejection rates.

We classified any application that was Awaiting Examination or Under Examination as Pending. The majority of these Pending applications are Awaiting Examination. Given that RFE must be filed by now we could have also grouped these with withdrawn applications. Doing so would not affect calculation of grant rate or our assessment of the role 3(d).

How might 3(d) affect whether or not an application is granted? In the process described above, 3(d) could directly lead to rejections in three main ways: (1) The examiner raises 3(d) in an FER, resulting in abandonment of the application, or (2) The controller raises 3(d) on reviewing arguments from response to FER, generating a rejection, or (3) A pre-grant opposition raises 3(d) objections, which are upheld in a Controller Report rejecting the application. Importantly, withdrawals of applications before RFEs are filed cannot be directly due to 3(d), since there are no examination documents prior to RFEs.

To examine the direct role of 3(d) in rejections, we collected information from FER and Controller Reports for applications that have rejections on the merits on the role of 3(d). This set includes all non-granted applications, except those withdrawn before a request for examination was made. For each of these "Rejected" applications we determined if 3(d) was listed as a reason for rejection, and, if so, if this was the only grounds for rejection: We thus further categorize the Rejected applications as: Rejected, No 3(d); Rejected 3(d) Only; Rejected 3(d) Plus.

\section{Brazil}

We obtained Brazilian national phase application numbers from the Derwent World Patents Index (and verified against information from PATSTAT). We obtained Brazilian outcomes by searching the INPI website. We dropped a small number of applications where PCT information on the national website did not match the original PCT number.

Classifying outcomes in Brazil is complicated because of the nature of Brazil's pharmaceutical patent system. As discussed in the text, Brazil has a shared examination system, with pharmaceutical patent applications examined by both the National Institute for Industrial Property (INPI) and the Ministry of Health's health surveillance agency (ANVISA). Pharmaceutical patents can only be granted if both INPI and ANVISA approve. From 2001 to 2012 INPI would examine applications first, and only if it approved the application (i.e. issued a technical report indicating that the application fulfilled the criteria for patentability in the patent law) would it be sent to 
ANVISA for subsequent review. As of May 2012 the workflow was inverted, such that INPI immediately forwards all pharmaceutical patent applications to ANVISA, where they are reviewed and then returned to INPI for subsequent examination.

To track outcomes, and to see ANVISA's role in outcomes, we searched all applications at both INPI and ANVISA. The INPI website provides data on each transaction that occurs at the patent office during the course of examination, allowing us to determine if applications were granted, rejected, withdrawn or abandoned, or still pending. While it is possible to know if an application was sent to ANVISA in the course of examination, from the INPI website alone it is not possible to determine what actions were taken by the examiners at the health agency. To overcome this constraint we also consulted two ANVISA documents that indicate the actions that the health agency has taken on each application it has received under the old workflow (through May 2012) and the new workflow (since May 2012). Using data from these two sources we determined whether Brazilian patent applications were granted, rejected, abandoned/withdrawn, or pending, and ANVISA's role.

Granted patents were approved by INPI and ANVISA. Applications with non-grant final determinations may be rejected or abandoned/withdrawn. For applications rejected by INPI, we determined whether the application was rejected by INPI alone or whether ANVISA was involved. Applications rejected solely by INPI are recorded as Rejected, INPI. The category Abandoned/Withdrawn refers to applications that were classified as "arquivado" by INPI, ordinarily on account of applicants not paying fees, never requesting examination in the first place, or not responding to INPI communication regarding non-substantive aspects of the application ("exigência"). When applicants fail to respond to substantive objections ("ciência") these are classified as Rejected, INPI.

Neither Rejected INPI nor Abandoned/Withdrawn categories involve ANVISA directly. Rejected, $P C$ refers to applications with final determinations of either reject or abandoned/withdrawn that, at some point in the process, were received by ANVISA. Rejected, $P C$ includes applications initially approved by the INPI and sent to ANVISA, but where ANVISA did not consent to a grant and the INPI subsequently rejected the application. This category also includes applications: (1) initially approved by the INPI and sent to ANVISA, but where in the course of ANVISA examining the application became "arquivado" at INPI, (2) where ANVISA finished its examination and denied consent, but rather than being rejected by INPI it ended abandoned or withdrawn; and (3) applications under the new workflow that ANVISA approved but were either rejected at INPI or abandoned/withdrawn before INPI made a final decision. Thus if an application was received by ANVISA at any point in the process and ended with a non-grant final determination it is classified as Rejected, $P C$.

Pending applications lack final determination. For applications filed under this old workflow, this includes a handful of so-called "frozen" applications (Shadlen 2011) where ANVISA denied consent but INPI did not issue a verdict and the application remained at the patent office, neither granted, rejected, nor abandoned/withdrawn.

The interpretation of pending applications is complicated by the introduction of the new workflow in 2012, whereby pharmaceutical patent applications go to ANVISA before INPI examines them. Pending applications may be: at ANVISA awaiting initial examination having been approved by INPI (old workflow), at INPI awaiting final determination after having been returned with a negative ruling by ANVISA (old workflow), at ANVISA awaiting initial examination (new 
workflow), at INPI awaiting examination having been returned with ANVISA's consent (new workflow).

\section{Argentina}

For Argentina, we used information from PATSTAT on all national filings, linked via priority numbers. Recall that Argentina is not a PCT country, so there are no "national phase" filings.

We obtained from the Argentinian patent office a dataset of all patent applications filed in Argentina from 2000-2005, with bibliographic and priority details, as well as information on final status. We then matched these against the Argentinian application numbers in PATSTAT to determine which of the applications in our sample were filed in Argentina. For Argentina we have four outcomes: Granted, Rejected, Abandoned/Withdrawn, and Pending. The Argentine patent office reports three different non-grant outcomes: abandoned, voluntary withdrawal, and forced withdrawal. Despite the seemingly self-explanatory labels, these do not map systematically on to different situations, and their use tends to be inconsistent as well, so to avoid misinterpretation we combine these three into the single category of Abandoned/Withdrawn. (Of these secondary applications filed in Argentina that we classify as abandoned/withdrawn, just under two thirds of were "forced withdrawal" and just under one third "abandoned," with less than 5 percent "voluntary wiithdrawal.")

For the subset of analyses where we consider the effects of Argentina's new examination guidelines, we used the date of the patent office decision. After the new guidelines were introduced in May 2012, all examination decisions were to be made in conformity with these new rules, including applications where examination had already commenced. As our data from the patent office include the dates of the patent office's decisions (not just the dates decisions were communicated to applicants, but the decisions themselves), we identify applications with decision dates after 8 May 2012 and distinguish these as being treated under the new guidelines. All Pending applications are, by definition, part of the new guidelines subset too. 


\section{Regression models}

As a complement to the graphical presentation in the paper, we also examined the main questions in the paper in a regression framework. Doing so allows us to control for application specific characteristics, and facilitates inference testing.

We estimated linear probability models relating the probability that an application i filed in country $\mathrm{j}$ is granted, with heteroskedasticity-consistent standard errors, clustered on the PCT application.

Model 1 examines differences in secondary patent grant rates by country. It is the regression analog of Figure 1(a) in the paper, but also controls for PCT filing year, the number of claims in the PCT application, family size, and whether their are any domestic inventors. The estimation sample includes 9,794 observations for the 2,964 secondary applications, one for each national filing in the US, EPO, Japan, India, Brazil, and Argentina. It shows that relative to the reference category, US applications, secondary grant rates are significantly lower in Japan, Brazil, India, and Argentina, with the largest differences in Brazil and Argentina. But there is no statistically significant difference between the U.S. and EPO. For each of the developing countries, we can reject the hypotheses that the grant rate is the same as in the US and EPO at the 1 percent level. We cannot reject the null that the Indian rate is equivalent to Japan $(\mathrm{p}=.59)$, but we can reject this for Brazil and Argentina (grant rate equivalent to Japan) each at the 1 percent level. Consistent with what we saw in the figures, the grant rate increases with family size. And we also see evidence here that having domestic inventors increases the grant rate, consistent with the idea of "home country bias" in international patenting (Jensen et al, 2006). But even after controlling for these factors, the patterns and magnitudes of differences in secondary grant rates between countries are similar to what Figure 1(a) showed. One thing to note is that the differences between India and Japan are less pronounced after controlling for family size, which we also saw in Figure 2 in the paper.

Model 2 is the main difference-in-difference model, the regression analog of comparing 1(a) and $1(b)$ in the paper. Here, the estimation sample includes all applications, primary and secondary. The model allows for differences in primary and secondary grant rates to vary by country. Only three countries have a significant difference in grant rates between primary and secondary patents: the US (where secondary patents have a 22 percentage point lower grant rate), Argentina (where secondary patents have a 8 percentage point lower grant rate), and India (where secondary patents have a 6 percentage point higher grant rate). As in the Figures in the text, there is no evidence that the gap between secondary and primary grant rates is differentially larger in India or Brazil than in the developed countries. For Argentina, the gap is significantly lower than that in the EPO $(p<.01)$ and Japan $(\mathrm{p}<.05)$.

Model 3 is estimated over secondary applications only, and includes application specific fixed effects. These fixed effects absorb any unobserved differences across applications, i.e. the coefficients on the country specific grant rates are based on within-application variation. (Of the variables listed above, the only one with within application variation, other than the country dummies, is the indicator for whether the application is domestic.) Note that unlike the secondary twins analyses from Figures 1(c) and 1(e) of the paper, identification here comes not from applications filed in all countries, but from grant rates for any applications filed in multiple countries. The overall patterns across countries are similar to those observed from Model 1. Secondary grant rates are significantly lower than the reference category (the US) in Japan, India, Brazil, and Argentina, each at the 1 percent level. (However there is no significant difference between the US and EPO.) The secondary patent grant rate is lowest in Brazil, followed by Argentina, then India. There is no statistically significant difference between the Argentinian and 
Brazilian grant rates $(\mathrm{p}=.07)$, but each have significantly lower grant rates than India at the 1 percent level.

\begin{tabular}{|c|c|c|c|}
\hline & $\begin{array}{c}(1) \\
\text { Granted }\end{array}$ & $\begin{array}{c}(2) \\
\text { Granted }\end{array}$ & $\begin{array}{c}(3) \\
\text { Granted }\end{array}$ \\
\hline $\mathrm{EP}$ & $\begin{array}{l}0.00594 \\
(0.624)\end{array}$ & $\begin{array}{c}-0.205^{* * *} \\
(0.000)\end{array}$ & $\begin{array}{l}0.0157 \\
(0.256)\end{array}$ \\
\hline JP & $\begin{array}{c}-0.235^{* * *} \\
(0.000)\end{array}$ & $\begin{array}{c}-0.427^{* * *} \\
(0.000)\end{array}$ & $\begin{array}{c}-0.208^{* * *} \\
(0.000)\end{array}$ \\
\hline BR & $\begin{array}{c}-0.584^{* * *} \\
(0.000)\end{array}$ & $\begin{array}{c}-0.815^{* * *} \\
(0.000)\end{array}$ & $\begin{array}{c}-0.505^{* * *} \\
(0.000)\end{array}$ \\
\hline IN & $\begin{array}{c}-0.224^{* * *} \\
(0.000)\end{array}$ & $\begin{array}{c}-0.501^{* * *} \\
(0.000)\end{array}$ & $\begin{array}{c}-0.146^{* * *} \\
(0.000)\end{array}$ \\
\hline AR & $\begin{array}{c}-0.553^{* * *} \\
(0.000)\end{array}$ & $\begin{array}{c}-0.696^{* * *} \\
(0.000)\end{array}$ & $\begin{array}{c}-0.468^{* * *} \\
(0.000)\end{array}$ \\
\hline PCT Year 2001 & $\begin{array}{r}-0.0295^{*} \\
(0.042)\end{array}$ & $\begin{array}{c}-0.00462 \\
(0.678)\end{array}$ & \\
\hline PCT Year 2002 & $\begin{array}{l}-0.0161 \\
(0.239)\end{array}$ & $\begin{array}{c}0.0269^{* *} \\
(0.009)\end{array}$ & \\
\hline Number of Claims & $\begin{array}{c}-0.000332 \\
(0.129)\end{array}$ & $\begin{array}{c}-0.000338^{*} \\
(0.033)\end{array}$ & \\
\hline Family size & $\begin{array}{c}0.0265^{* * *} \\
(0.000)\end{array}$ & $\begin{array}{c}0.0276^{* * *} \\
(0.000)\end{array}$ & \\
\hline Any Domestic Inventor & $\begin{array}{c}0.0922^{* * *} \\
(0.000)\end{array}$ & $\begin{array}{c}0.0985^{* * *} \\
(0.000)\end{array}$ & \\
\hline Secondary, US & & $\begin{array}{c}-0.216^{* * *} \\
(0.000)\end{array}$ & \\
\hline Secondary, EP & & $\begin{array}{c}-0.00327 \\
(0.813)\end{array}$ & \\
\hline Secondary, JP & & $\begin{array}{l}-0.0239 \\
(0.073)\end{array}$ & \\
\hline Secondary, BR & & $\begin{array}{r}0.0123 \\
(0.294)\end{array}$ & \\
\hline Secondary, IN & & $\begin{array}{l}0.0552^{*} \\
(0.044)\end{array}$ & \\
\hline Secondary, AR & & $\begin{array}{c}-0.0758^{* * *} \\
(0.000)\end{array}$ & \\
\hline Constant & $\begin{array}{c}0.289^{* * *} \\
(0.000)\end{array}$ & $\begin{array}{l}0.470^{* * *} \\
(0.000)\end{array}$ & $\begin{array}{c}0.509^{* * *} \\
(0.000)\end{array}$ \\
\hline Observations & 9794 & 16174 & 9794 \\
\hline PCT fixed effects & No & $\mathrm{No}$ & Yes \\
\hline
\end{tabular}

